\title{
1 Orthostatic intolerance in adults with long COVID was not associated 2 with postural orthostatic tachycardia syndrome
}

Ann Monaghan ${ }^{1}$, Glenn Jennings ${ }^{1}$, Feng Xue ${ }^{1}$, Lisa Byrne ${ }^{2}$, Eoin Duggan ${ }^{1,2}$, Roman RomeroOrtuno $^{1,2} *$

${ }^{1}$ Discipline of Medical Gerontology, School of Medicine, Trinity College Dublin, Dublin, Ireland

${ }^{2}$ Falls and Syncope Unit, Mercer's Institute for Successful Ageing, St James's Hospital, Dublin,

8 Ireland

9 * Correspondence:

10 Prof. Roman Romero-Ortuno, 6th Floor, Mercer's Institute for Successful Ageing (MISA), St James's Hospital, Dublin 8, Ireland. Telephone: +353 1896 3555. Fax: +353 1896 3407. Email: romeroor@tcd.ie

Keywords: Long-COVID; Orthostatic Intolerance; Hemodynamics; Tilt-Table Test; Postural

\section{Abstract}

In this observational cross-sectional study, we investigated predictors of orthostatic intolerance (OI) in adults with long COVID. Participants underwent a 3-minute active stand (AS) with Finapres® NOVA, followed by a 10-minute unmedicated 70-degree head-up tilt test. 85 participants were included (mean age 46 years, range 25-78; 74\% women), of which 56 (66\%) reported OI during AS $\left(\mathrm{OI}_{\mathrm{AS}}\right) \cdot \mathrm{OI}_{\mathrm{AS}}$ seemed associated with female sex, more fatigue and depressive symptoms, and greater inability to perform activities of daily living (ADL), as well as a higher heart rate (HR) at the lowest systolic blood pressure (SBP) point before the $1^{\text {st }}$ minute post-stand (mean $\mathrm{HR}_{\text {nadir }}$ : 88 vs $75 \mathrm{bpm}$, $\mathrm{P}=0.004)$. In a regression model also including age, sex, fatigue, depression, ADL inability, and peak $\mathrm{HR}$ after the nadir SBP, $\mathrm{HR}_{\text {nadir }}$ was the only $\mathrm{OI}_{\mathrm{AS}}$ predictor $(\mathrm{OR}=1.09,95 \% \mathrm{CI}$ : 1.01-1.18, $\mathrm{P}=0.027)$. 22 participants had initial $(\mathrm{iOH})$ and 5 classical $(\mathrm{cOH})$ orthostatic hypotension, but neither correlated with $\mathrm{OI}_{\mathrm{AS}} .71$ participants proceeded to tilt, of which 28 had OI during tilt $\left(\mathrm{OI}_{\text {tilt }}\right)$. Of the 53 who had a 10-minute tilt, 7 (13\%) fulfilled hemodynamic postural orthostatic tachycardia syndrome (POTS) criteria, but 6 did not report $\mathrm{OI}_{\text {tilt }} . \mathrm{OI}_{\mathrm{AS}}$ was associated with a higher initial HR on AS, which after 1 minute equalized with the non-OI $\mathrm{AS}_{\mathrm{S}}$ group. Despite these initial orthostatic HR differences, POTS was infrequent and largely asymptomatic. ClinicalTrials.gov Identifier: NCT05027724 (retrospectively registered on August 30, 2021). 
Long COVID or post-COVID-19 syndrome first gained recognition among social support groups and later in scientific and medical communities (Yong, 2021). This condition is not well understood as it affects COVID-19 survivors at all ages and levels of disease severity, with or without pre-existing comorbidities, and regardless of hospitalisation status (Vanichkachorn et al., 2021;Yong, 2021). A common symptom is fatigue, with or without organ-specific symptoms (Jennings et al., 2021;Rogers et al., 2021), which may result in negative impacts on resumption of functional and occupational activities (Yan et al., 2021). A systematic review reported that symptoms of mild COVID-19 may persist after 3 weeks in a third of patients (van Kessel et al., 2021). Another study reported that up to one in four patients with mild COVID-19 were still experiencing symptoms after one year (Rank et al., 2021); however, data on the exact prevalence and long-term effects of long COVID are still lacking (Zarei et al., 2021), with an urgent need for research in different populations and settings (Michelen et al., 2021). To aid clinicians and researchers, on 6 October 2021 the World Health Organization (WHO) issued a clinical case definition of post COVID-19 condition, obtained by a Delphi consensus (WHO, 2021), as follows: "Post COVID-19 condition occurs in individuals with a history of probable or confirmed SARS-CoV-2 infection, usually 3 months from the onset of COVID-19 with symptoms that last for at least 2 months and cannot be explained by an alternative diagnosis. Common symptoms include fatigue, shortness of breath, cognitive dysfunction but also others, which generally have an impact on everyday functioning. Symptoms may be new onset, following initial recovery from an acute COVID-19 episode, or persist from the initial illness. Symptoms may also fluctuate or relapse over time".

The neurological and cardiovascular overlap in some long COVID symptoms, and in particular the reported occurrence of orthostatic intolerance (OI) (Dani et al., 2021;Paterson et al., 2021; Shah et al., 2021), have raised the hypothesis as to whether some long COVID patients could have measurable autonomic nervous system impairments (Del Rio et al., 2020;Goldstein, 2020;Keyhanian et al., 2020;Barizien et al., 2021;Becker, 2021;Larsen et al., 2021) such as orthostatic hypotension (OH) or postural orthostatic tachycardia syndrome (POTS) (Blitshteyn and Whitelaw, 2021;Johansson et al., 2021; Raj et al., 2021). In this light, we conducted a cross-sectional observational study on a cohort of long COVID participants to fulfil the following objectives: (1) establish the prevalence of OI, both during an active stand (AS) test and a tilt test; (2) establish the prevalence of OH and POTS in this cohort; and (3) study haemodynamic and non-haemodynamic predictors of OI.

\section{Methods}

\subsection{Study and cohort description}

This was a cross-sectional observational study on a participant cohort recruited for the TROPIC (Technology assisted solutions for the Recognition of Objective Physiological Indicators of postCoronavirus-19 fatigue) investigation at Trinity College Dublin and St James's Hospital Dublin, Ireland. The study received full ethical and regulatory approvals. For the reporting, we followed STROBE guidelines (von Elm et al., 2007). history of confirmed or suspected SARS-CoV-2 infection; (3) experiencing prolonged symptoms such as fatigue; (4) able to mobilise independently (with or without aid); (5) able to transfer independently or with minimal assistance of one person from lying to standing; and (6) able to give 
Participants were recruited from the following sources in our hospital: (1) falls and syncope unit; (2)

81

82

83

86

87

88

89

90

92

93

94

95

96

97

98

99

100

101

102

103

104

105

106

107

108

109

110

111

112

113

114

115

116

117

118

119

120

121

122

geriatric day hospital; (3) post COVID-19 outpatient clinic; (4) staff who had contracted COVID-19; and (5) participants from earlier post-COVID-19 research who had consented to be contacted for further studies. In addition, we also considered (6) self-referrals. COVID-19 and non-COVID-19 exclusion criteria for enrolment are outlined in the Supplementary Information (section 1).

Prior to enrolment, participants were provided with a Participant Information Leaflet explaining the aims and procedures of the study. All participants provided explicit, informed, and voluntary consent to partake in the study, were explained the benefits and risks of participating in the research, and had the opportunity to discuss the study and ask questions. Participants were given the opportunity to withdraw from the study at any point and to forego completing components of the assessment protocol as desired.

\subsection{Procedures}

Participants underwent a 3-minute active stand (AS) with Finapres ${ }^{\circledR}$ NOVA, followed by a 10minute unmedicated 70-degree head-up tilt test. During both, participants had frontal lobe oxygenation monitoring via PortaLite ${ }^{\circledR}$ near-infrared spectroscopy (NIRS). All testing procedures complied with the local hand hygiene, sanitation, personal protective equipment (PPE), and research training protocols. We also considered international best practice recommendations for autonomic testing during the COVID-19 pandemic (Figueroa et al., 2020;Guaraldi et al., 2020;Sinn et al., 2021).

For the active stand, participants underwent a lying-to-standing orthostatic test with non-invasive beat-to-beat blood pressure monitoring using digital photoplethysmography (Finapres® NOVA, Finapres Medical Systems, Amsterdam, The Netherlands). The height correction unit was zeroed and implemented as per manufacturer's specifications. A 5-lead continuous electrocardiogram (ECG) was acquired throughout the test. During the supine rest period, an oscillometric brachial blood pressure measurement was obtained from the non-monitored (right) arm for calibration purposes, once the PhysioCal repetition rate was 70 beats or more (Wesseling, 1996). After at least 5 minutes of uninterrupted supine rest, a total lying duration of no more than 10 minutes, and a 10 -second countdown, participants were asked to stand, unaided, as quick as possible. The PhysioCal was turned off just before the stand and switched back on at 1-minute post-stand. After standing, SBP, DBP, and HR were monitored for three minutes. Throughout the recording, participants were asked to remain motionless and in silence with the monitored arm (left) resting extended by the side, except for reporting any symptoms of concern. Immediately after the stand, and at the end of the test, participants were asked to report whether they had felt any symptoms of dizziness, light-headedness, or any other abnormal symptoms.

For the tilt procedure, which was medically supervised and started after a brief non-monitored break following AS, participants were affixed to an electrically motorized tilt table with footboard support and approximately 10 seconds of travel time between $0^{\circ}$ and $70^{\circ}$ (Agasan KT-1060/E, AGA Sanitätsartikel GmbH, Löhne, Germany). Throughout the tilt, participants underwent Finapres ${ }^{\circledR}$ NOVA monitoring (with PhysioCal on and continuous ECG monitoring) during an initial period of uninterrupted supine rest of at least 5 minutes (with a total lying duration of no more than 10 minutes) and a subsequent head-up tilt to $70^{\circ}$ for 10 minutes or until symptoms developed. An oscillometric brachial blood pressure was also obtained during supine rest. During the head-up tilt phase, participants were asked to report whether they felt any symptoms of dizziness, lightheadedness, or any other abnormal symptoms, at which point participants were offered to be tilted 
123 down. Even without symptoms, if the head-up tilt elicited hypotension (defined as $\mathrm{SBP}<90 \mathrm{mmHg}$ ),

124 the tilt was aborted.

125 For the NIRS-based monitoring of regional cerebral oxygenation of the left frontal lobe during both

126 AS and tilt, we used an optical sensor (PortaLite®, Artinis Medical Systems B.V., Elst, The

127 Netherlands), applied approximately $3 \mathrm{~cm}$ to the left of the midline of the forehead and $3.5 \mathrm{~cm}$ above

128 the bridge of the nose. A close-woven bandage was affixed around the head over the sensor to

129 remove ambient lighting and to exert comfortable pressure for effective contact between the probe

130 and the skin.

\section{$131 \quad 2.3 \quad$ Hemodynamic data extraction}

132 For SBP, DBP and HR, values were noted at the various timepoints of AS and head-up tilt from the

133 Finapres ${ }^{\circledR}$ NOVA display screen in accordance with the following standard operating procedure

134 (SOP): baseline values were collected at 60 seconds prior to AS or head-up tilt, and subsequently at

135 the start of every minute after each procedure. As regards nadir values, for the AS they were noted at

136 the lowest point of SBP following completion of standing and prior to the first minute post-stand; in

137 the case of the tilt, they were noted at the lowest point of SBP reached between completion of the

138 head-up tilt manoeuvre and prior to the first minute post-tilt. For the AS, we also modelled the peak

139 HR after the nadir SBP, defined as the maximum of the HR readings obtained at 1, 2 and 3 minutes.

140 NIRS values were noted following the same SOP from a laptop display connected to the PortaLite ${ }^{\circledR}$

141 device via OxySoft ${ }^{\circledR}$ software (version 3.2.70), from which we extracted Tissue Saturation Index

142 (TSI) values as the percentage ratio of oxygenated haemoglobin concentration to the total

143 concentration of haemoglobin (Claffey et al., 2020).

\section{$144 \quad 2.4 \quad$ Orthostatic hypotension definitions}

145 Initial orthostatic hypotension (iOH) on AS was defined as a difference of $>40 \mathrm{mmHg} \mathrm{SBP}$ and/or $146>20 \mathrm{mmHg}$ DBP between baseline and nadir values (Freeman et al., 2011).

Classical orthostatic hypotension on AS $\left(\mathrm{cOH}_{\mathrm{AS}}\right)$ was defined as a difference of $\geq 20 \mathrm{mmHg}$ SBP and/or $\geq 10$ DBP between each baseline value and its minimum reading between minutes 1, 2, and 3

150 (Freeman et al., 2011). Nadir values were not included in this definition for clear differentiation with $151 \mathrm{iOH}$ and to better reflect $\mathrm{cOH}_{\mathrm{AS}}$ as normally measured in routine clinical practice with an interval measurement device (Breeuwsma et al., 2018).

Classical orthostatic hypotension on tilt $\left(\mathrm{cOH}_{\text {tilt }}\right)$ was defined as a difference of $\geq 20 \mathrm{mmHg}$ SBP and/or $\geq 10$ DBP between each baseline value and its minimum reading between nadir and minutes 1 , 2, and 3. Nadir was included in this case because $\mathrm{iOH}$ is only associated with active rising (Wieling et al., 2007).

\section{$158 \quad 2.5 \quad$ POTS hemodynamic definition}

159 We computed the maximum HR between nadir and minutes 1 to 10 (or the available minutes in case of early tilt termination), to which we subtracted baseline HR, and POTS was defined in hemodynamic terms as a difference of $\geq 30 \mathrm{bpm}$ in the absence of $\mathrm{cOH}_{\text {tilt }}$ (Freeman et al., 2011).

\section{$162 \quad 2.6 \quad$ Other measures}

163 For the characterisation of the cohort, we collected measures including: 
- Demographics: age, sex.

- Anthropometrics: body mass index $\left(\mathrm{Kg} / \mathrm{m}^{2}\right)$.

166 - Proportion of third level education (i.e., primary university degree or higher).

- Past medical history including previous or current smoker, hypertension, heart disease (e.g., previous heart attack, angina, congestive heart failure, atrial fibrillation), diabetes mellitus (yes or no).

\subsection{Statistical analyses}

Statistics were computed with IBM® SPSS ${ }^{\circledR}$ Statistics for Windows, Version 26.0, Armonk, NY: IBM Corp. Descriptives were given with count and percentage (\%), mean with standard deviation (SD), median with interquartile range (IQR), and range. We utilised the SPSS Chart Builder to visualise hemodynamic differences between subgroups via cluster line chart with representation of 95\% confidence intervals (CI) around means. To compare characteristics between subgroups, we utilised the non-parametric 2-sided Mann-Whitney U test for continuous variables, and the Chisquare test for dichotomous characteristics. In the latter case, we used the 2-sided Fisher's exact test when at least one cell had an expected count of $<5$. To establish independent predictors of dichotomous group membership, we computed logistic regression models, and for each predictor extracted the Odds Ratio (OR) and 95\% CI for the OR. Multicollinearity checks were conducted. Statistical significance was defined as $\mathrm{P}<0.05$.

\subsection{Ethical approval}

201

This study received full approval by the St James's Hospital/Tallaght University Hospital Joint Research Ethics Committee (Submission Number: 104: TROPIC; Approval Date: 4 May 2021) and the St James's Hospital Research \& Innovation Office (Reference: 6566; Approval Date: 14 May 2021). The study was performed in accordance with the ethical standards laid down in the 1964 Declaration of Helsinki and its later amendments. All participants gave their informed consent prior to their inclusion in the study. All aspects of the study were executed in compliance with the General Data Protection regulation (GDPR), and Irish regulations including the Health Research Regulations and the Data Protection Act 2018. 


\section{Results}

209

210

211

212

213

214

215

216

217

218

219

220

221

222

223

224

225

226

227

228

229

230

231

232

233

234

235

236

237

238

239

240

241

242

243

244

245

246

247

248

249

250

251

252

253

254

255

256

257

258

Of 92 consecutive participants recruited to the study between May and September 2021, 85 (92.4\%) had an AS. Mean age was 46.0 years (SD 10.2, range 25-78), and 63 (74.1\%) were women. Overall, fatigue was a very prevalent long COVID symptom in this cohort (93.5\%), with other common (>50\%) symptoms being shortness of breath (69.6\%), sleeping problems $(65.2 \%)$, ongoing headaches (64.1\%), dizziness $(63.0 \%)$, heart palpitations $(60.9 \%)$, brain fog $(59.8 \%)$, muscular pain (54.3\%), and chest tightness (53.3\%). Table 1 shows additional descriptives of the 85 participants who had an AS. $36.5 \%$ had a BMI in the obesity range $\left(\geq 30 \mathrm{Kg} / \mathrm{m}^{2}\right)$, and $1.2 \%$ in the underweight range $(<18.5$ $\mathrm{Kg} / \mathrm{m}^{2}$ ). The majority $(62.4 \%)$ had third level education and $42.4 \%$ were current or former smokers. Other than hypertension (17.6\%), prevalences of heart disease and diabetes were very low $(<5 \%)$, and there were no instances of Parkinson's disease or other known conditions with risk of autonomic impairment. A fifth were on antidepressant medications and less than $20 \%$ were on antihypertensives, beta blockers or benzodiazepines. In terms of COVID-19 history, all but 2 participants were at least 3 months from the onset of COVID-19, a quarter had been hospitalised, and $81.2 \%$ met criteria for WHO clinical case definition of post COVID-19 condition. Median scores for CFQ, CES-D and IES-R were 26, 21 and 26, respectively.

During the AS, 56 participants (65.9\%) reported $\mathrm{OI}_{\mathrm{As}}$. The frequencies of $\mathrm{OI}_{\mathrm{AS}}$ symptoms were as follows: "slightly light-headed" ( $\mathrm{n}=31,55.4 \%)$, "light-headed" $(\mathrm{n}=15,26.8 \%)$, "dizzy" $(\mathrm{n}=5,8.9 \%)$, "slightly dizzy" $(\mathrm{n}=4,7.1 \%)$, and "very light-headed" $(\mathrm{n}=1,1.8 \%) .2$ of the 85 participants had an early AS termination due to non-hypotensive/cardiac $\mathrm{OI}_{\mathrm{AS}}$ symptoms $\left(\mathrm{n}=1\right.$ before the $1^{\text {st }}$ minute, and $\mathrm{n}=1$ before the $3^{\text {rd }}$ minute). Table 1 shows the comparison between $\mathrm{OI}_{\mathrm{AS}}$ and non-OI $\mathrm{IS}_{\mathrm{AS}}$ subgroups. 22 (25.9\%) participants fulfilled criteria for $\mathrm{iOH}$, and $5(5.9 \%)$ for $\mathrm{cOH}_{\mathrm{AS}}$, and neither of the two $\left(\mathrm{P}=0.952\right.$ an $\mathrm{P}=0.654$, respectively) were significantly associated with $\mathrm{OI}_{\mathrm{AS}}$. $\mathrm{OI}_{\mathrm{AS}}$ was more likely in women $(\mathrm{P}=0.019)$ and was associated with higher $\mathrm{CFQ}(\mathrm{P}=0.042)$ and $\mathrm{CES}-\mathrm{D}(\mathrm{P}=0.021)$ scores. The presence of $\mathrm{OI}_{\mathrm{AS}}$ was more likely to be associated with the activities of daily living impairment criterion used for our application of the WHO clinical case definition $(\mathrm{P}=0.011)$, with virtually all participants with $\mathrm{OI}_{\mathrm{AS}}(96.3 \%)$ reporting too little energy to do the things they wanted to do in the past month. 
medRxiv preprint doi: https://doi.org/10.1101/2021.12.19.21268060; this version posted December 21, 2021. The copyright holder for this preprint (which was not certified by peer review) is the author/funder, who has granted medRxiv a license to display the preprint in perpetuity.

It is made available under a CC-BY-NC-ND 4.0 International license .

Running Title

Table 1. Clinical characteristics of the overall cohort, as well as comparison between $\mathrm{OI}_{\mathrm{AS}}$ and non-OI $\mathrm{AS}_{\mathrm{AS}}$ subgroups. $\mathrm{OI}_{\mathrm{AS}}$ : orthostatic intolerance during active stand; SD: standard deviation; BMI: body mass index; IQR: interquartile range; CFQ: Chalder Fatigue Scale; CES-D: Center for Epidemiological Studies Depression scale; IES-R: Impact of Event Scale - Revised; iOH: initial orthostatic hypotension; $\mathrm{cOH}_{\mathrm{AS}}$ : classical orthostatic hypotension during active stand.

\begin{tabular}{|c|c|c|c|c|}
\hline Characteristic & Overall cohort $(\mathrm{n}=85)$ & No OI ${ }_{A S}(n=29)$ & $\mathrm{OI}_{\mathrm{AS}}(\mathrm{n}=56)$ & $\mathrm{P}$ \\
\hline Mean age, years (SD) & $\begin{array}{c}46.0(10.2) \\
\text { (range 25-78) }\end{array}$ & $49.1(11.9)$ & $44.5(9.0)$ & $0.075^{\mathrm{a}}$ \\
\hline Female sex $(\%)$ & 74.1 & 58.6 & 82.1 & $0.019^{\mathrm{b} z}$ \\
\hline Mean BMI, $\mathrm{Kg} / \mathrm{m}^{2}(\mathrm{SD})$ & $28.3(5.1)$ & $27.2(4.3)$ & $28.9(5.4)$ & $0.148^{\mathrm{a}}$ \\
\hline $\begin{array}{l}\text { Mean 5-chair stands } \\
\text { time, seconds (SD) }\end{array}$ & $15.0(10.4)$ & $12.8(5.1)$ & $16.4(12.4)$ & $0.409^{\mathrm{a}}$ \\
\hline $\begin{array}{l}\text { Third level education } \\
(\%)\end{array}$ & 62.4 & 53.8 & 69.6 & $0.164^{\mathrm{b}}$ \\
\hline $\begin{array}{l}\text { Previous or current } \\
\text { smoker }(\%)\end{array}$ & 42.4 & 56.0 & 40.0 & $0.182^{b}$ \\
\hline $\begin{array}{l}\text { History of hypertension } \\
(\%)\end{array}$ & 17.6 & 20.7 & 16.1 & $0.596^{\mathrm{b}}$ \\
\hline $\begin{array}{l}\text { History of heart disease } \\
(\%)\end{array}$ & 3.5 & 6.9 & 1.8 & $0.267^{\mathrm{c}}$ \\
\hline History of diabetes $(\%)$ & 3.5 & 6.9 & 1.8 & $0.267^{\mathrm{c}}$ \\
\hline On antihypertensive (\%) & 16.5 & 24.1 & 12.5 & $0.220^{\circ}$ \\
\hline On beta blocker (\%) & 15.3 & 13.8 & 16.1 & $1.000^{\mathrm{c}}$ \\
\hline On antidepressant $(\%)$ & 20.0 & 17.2 & 21.4 & $0.647^{\mathrm{b}}$ \\
\hline On benzodiazepine (\%) & 3.5 & 3.4 & 3.6 & $1.000^{\mathrm{c}}$ \\
\hline $\begin{array}{l}\text { Median days post- } \\
\text { COVID-19 diagnosis } \\
\text { (IQR) }\end{array}$ & $\begin{array}{c}302.0(333.0) \\
\text { (range } 39-655)\end{array}$ & $249.0(353.5)$ & $317.5(297.8)$ & $0.628^{\mathrm{a}}$ \\
\hline $\begin{array}{l}\text { Hospitalised with } \\
\text { COVID-19 }(\%)\end{array}$ & 25.9 & 26.9 & 27.8 & $0.936^{\mathrm{b}}$ \\
\hline $\begin{array}{l}\text { At least } 3 \text { months (>91 } \\
\text { days) from the onset of } \\
\text { COVID-19 }(\%)\end{array}$ & 97.6 & 96.0 & 98.1 & $0.547^{\mathrm{c}}$ \\
\hline $\begin{array}{l}\text { Post COVID-19 } \\
\text { symptoms for at least } 2 \\
\text { months }(\%)\end{array}$ & 98.8 & 100 & 98.1 & $1.000^{\mathrm{c}}$ \\
\hline $\begin{array}{l}\text { In the past month, I } \\
\text { have had too little } \\
\text { energy to do the things I } \\
\text { wanted to do }(\%)\end{array}$ & 83.5 & 76.0 & 96.3 & $0.011^{\mathrm{c}}$ \\
\hline $\begin{array}{l}\text { Median CFQ score } \\
\text { (IQR) }\end{array}$ & $26.0(8.0)$ & $24.0(10.0)$ & $27.0(7.8)$ & $0.042^{\mathrm{a}^{*}}$ \\
\hline $\begin{array}{l}\text { Median CES-D score } \\
\text { (IQR) }\end{array}$ & $21.0(17.0)$ & $16.0(16.8)$ & $24.0(16.0)$ & $0.021^{\mathrm{a}^{*}}$ \\
\hline $\begin{array}{l}\text { Median IES-R score } \\
\text { (IQR) }\end{array}$ & $25.5(28.8)$ & $18.5(30.3)$ & $31.0(28.5)$ & $0.106^{\mathrm{a}}$ \\
\hline $\mathrm{IOH}$ & 25.9 & 33.3 & 34.1 & $0.952^{\mathrm{b}}$ \\
\hline $\mathrm{cOH}_{\mathrm{AS}}$ & 5.9 & 3.6 & 7.5 & $0.654^{\mathrm{c}}$ \\
\hline
\end{tabular}

${ }^{\mathrm{a}}$ 2-sided Mann-Whitney U test; ${ }^{\mathrm{b}}$ Chi-square test; ${ }^{\mathrm{c}}$ 2-sided Fisher's exact test; ${ }^{*}$ statistically significant $(\mathrm{P}<0.05)$.

In terms of the haemodynamic comparison between $\mathrm{OI}_{\mathrm{AS}}$ and non-OI $\mathrm{AS}_{\mathrm{AS}}$ subgroups (Table 2), participants reporting $\mathrm{OI}_{\mathrm{AS}}$ had a higher $\mathrm{HR}$ at the lowest SBP point before the first minute post-stand (mean $\mathrm{HR}_{\text {nadir: }} 88$ vs 75 bpm, $\mathrm{P}=0.004$ ). There were no baseline or subsequent HR differences, or any $\mathrm{BP}$ or NIRS differences. In the haemodynamic visualisation in Figure 1, participants' finishing BP levels (at 3 minutes) seemed higher than at baseline, with 95\% CIs around means that clearly did not overlap in the case of DBP (panel b), but without any suggested differences between $\mathrm{OI}_{\mathrm{AS}}$ and non$\mathrm{OI}_{\mathrm{AS}}$ subgroups. On closer inspection, for the overall cohort, there was a statistically significant difference between baseline and 3-minute DBP (mean 81.0 vs $93.1 \mathrm{mmHg}$, paired samples t-test $\mathrm{P}<0.001)$. 
medRxiv preprint doi: https://doi.org/10.1101/2021.12.19.21268060; this version posted December 21, 2021. The copyright holder for this preprint (which was not certified by peer review) is the author/funder, who has granted medRxiv a license to display the preprint in perpetuity.

It is made available under a CC-BY-NC-ND 4.0 Rrithostaticisetolerance in long COVID

Table 2. Haemodynamic comparison between $\mathrm{OI}_{\mathrm{AS}}$ and non-OI $\mathrm{OI}_{\mathrm{AS}}$ subgroups. AS: active stand; $\mathrm{OI}_{\mathrm{AS}}$ : orthostatic intolerance during AS; SD: standard deviation; SBP: systolic blood pressure; DBP: diastolic blood pressure; HR: heart rate; bpm: beats per minute; TSI: tissue saturation index.

\begin{tabular}{|c|c|c|c|}
\hline & $\begin{array}{l}\operatorname{No~OI}_{\mathrm{AS}} \\
\text { (initial and final } n=29 \text { ) }\end{array}$ & $\begin{array}{c}\mathrm{OI}_{\mathrm{AS}} \\
\text { (initial } \mathrm{n}=56 \text { ) } \\
\text { (final } \mathrm{n}=54 \text { ) } \\
\end{array}$ & $\mathrm{P}$ \\
\hline Mean oscillometric baseline SBP, mmHg (SD) & $\begin{array}{c}131.9(13.3) \\
\text { (range 103-158) }\end{array}$ & $\begin{array}{c}131.2(15.0) \\
\text { (range 106-169) }\end{array}$ & $0.541^{\mathrm{a}}$ \\
\hline AS: mean baseline SBP, mmHg (SD) & $135.0(12.8)$ & $131.7(14.3)$ & $0.216^{a}$ \\
\hline AS: mean nadir SBP, mmHg (SD) & $103.1(18.9)$ & $99.9(16.6)$ & $0.500^{2}$ \\
\hline AS: mean SBP at 1 minute, $\mathrm{mmHg}(\mathrm{SD})$ & $139.8(18.0)$ & $142.6(15.8)$ & $0.621^{2}$ \\
\hline AS: mean SBP at 2 minutes, $\mathrm{mmHg}(\mathrm{SD})$ & $141.0(15.2)$ & $139.9(16.7)$ & $0.570^{2}$ \\
\hline AS: mean SBP at 3 minutes, $\mathrm{mmHg}$ (SD) & $142.0(12.8)$ & $140.6(17.0)$ & $0.328^{a}$ \\
\hline Mean oscillometric baseline DBP, mmHg (SD) & $\begin{array}{c}80.7(7.9) \\
\text { (range 63-97) }\end{array}$ & $\begin{array}{c}80.9(9.7) \\
\text { (range 66-109) } \\
\end{array}$ & $0.700^{\mathrm{a}}$ \\
\hline AS: mean baseline DBP, $\mathrm{mmHg}$ (SD) & $80.7(7.4)$ & $81.0(10.1)$ & $0.947^{\mathrm{a}}$ \\
\hline AS: mean nadir DBP, $\mathrm{mmHg}(\mathrm{SD})$ & $75.8(13.3)$ & $77.8(20.2)$ & $0.868^{\mathrm{a}}$ \\
\hline AS: mean DBP at 1 minute, $\mathrm{mmHg}(\mathrm{SD})$ & $91.0(10.2)$ & $93.0(11.1)$ & $0.419^{\mathrm{a}}$ \\
\hline AS: mean DBP at 2 minutes, $\mathrm{mmHg}(\mathrm{SD})$ & $89.8(9.3)$ & $93.0(11.7)$ & $0.233^{\mathrm{a}}$ \\
\hline AS: mean DBP at 3 minutes, $\mathrm{mmHg}$ (SD) & $93.4(9.3)$ & $93.1(12.6)$ & $0.680^{2}$ \\
\hline AS: mean baseline HR, bpm (SD) & $\begin{array}{c}67.3(11.0) \\
\text { (range } 49-94)\end{array}$ & $\begin{array}{c}71.4(12.9) \\
\text { (range } 50-113 \text { ) } \\
\end{array}$ & $0.210^{\mathrm{a}}$ \\
\hline AS: mean nadir HR, bpm (SD) & $74.6(12.3)$ & $88.4(19.6)$ & $0.004^{\mathrm{a}}$ \\
\hline AS: mean HR at 1 minute, bpm (SD) & $79.3(13.5)$ & $80.0(15.8)$ & $0.948^{\mathrm{a}}$ \\
\hline AS: mean HR at 2 minutes, bpm (SD) & $80.2(12.5)$ & $83.7(16.6)$ & $0.451^{\mathrm{a}}$ \\
\hline AS: mean HR at 3 minutes, bpm (SD) & $81.1(13.2)$ & $84.5(15.6)$ & $0.352^{\mathrm{a}}$ \\
\hline AS: peak HR after the nadir SBP, bpm (SD) & $83.1(13.7)$ & $86.5(16.2)$ & $0.434^{\mathrm{a}}$ \\
\hline AS: mean baseline TSI, \% (SD) & $\begin{array}{c}68.9(3.3) \\
\text { (range } 61-78)\end{array}$ & $\begin{array}{c}69.1(7.4) \\
\text { (range } 32-82 \text { ) }\end{array}$ & $0.852^{\mathrm{a}}$ \\
\hline AS: mean nadir TSI, \% (SD) & $68.0(3.8)$ & $68.3(8.3)$ & $0.510^{2}$ \\
\hline AS: mean TSI at 1 minute, $\%$ (SD) & $67.3(2.8)$ & $67.6(8.4)$ & $0.384^{\mathrm{a}}$ \\
\hline AS: mean TSI at 2 minutes, $\%$ (SD) & $67.1(2.8)$ & $67.4(8.3)$ & $0.490^{2}$ \\
\hline AS: mean TSI at 3 minutes, $\%$ (SD) & $67.4(3.1)$ & $67.8(6.1)$ & $0.878^{\mathrm{a}}$ \\
\hline
\end{tabular}

2 of the 85 participants had an early AS termination ( $\mathrm{n}=1$ before the $1^{\text {st }}$ minute, $\mathrm{n}=1$ before the $3^{\text {rd }}$ minute), both due to non-hypotensive/cardiac $\mathrm{OI} \mathrm{I}_{\mathrm{AS}}$ symptoms. ${ }^{\mathrm{a}} 2$-sided Mann-Whitney U test; ${ }^{\mathrm{b}}$ Chi-square test; ${ }^{*}$ statistically significant $(\mathrm{P}<0.05)$. 
medRxiv preprint doi: https://doi.org/10.1101/2021.12.19.21268060; this version posted December 21, 2021. The copyright holder for this preprint (which was not certified by peer review) is the author/funder, who has granted medRxiv a license to display the preprint in perpetuity.

311

312

313

314

315

316

317

Fig. 1. Haemodynamic visualisation of $\mathrm{OI}_{\mathrm{AS}}(\mathrm{n}=56)$ and non- $\mathrm{OI}_{\mathrm{AS}}(\mathrm{n}=29)$ groups; a: systolic blood pressure (SBP); b: diastolic blood pressure (DBP); c: heart rate (HR); d: tissue saturation index (TSI); bpm: beats per minute; CI: confidence interval.

$\underline{\text { a: systolic blood pressure (SBP) }}$

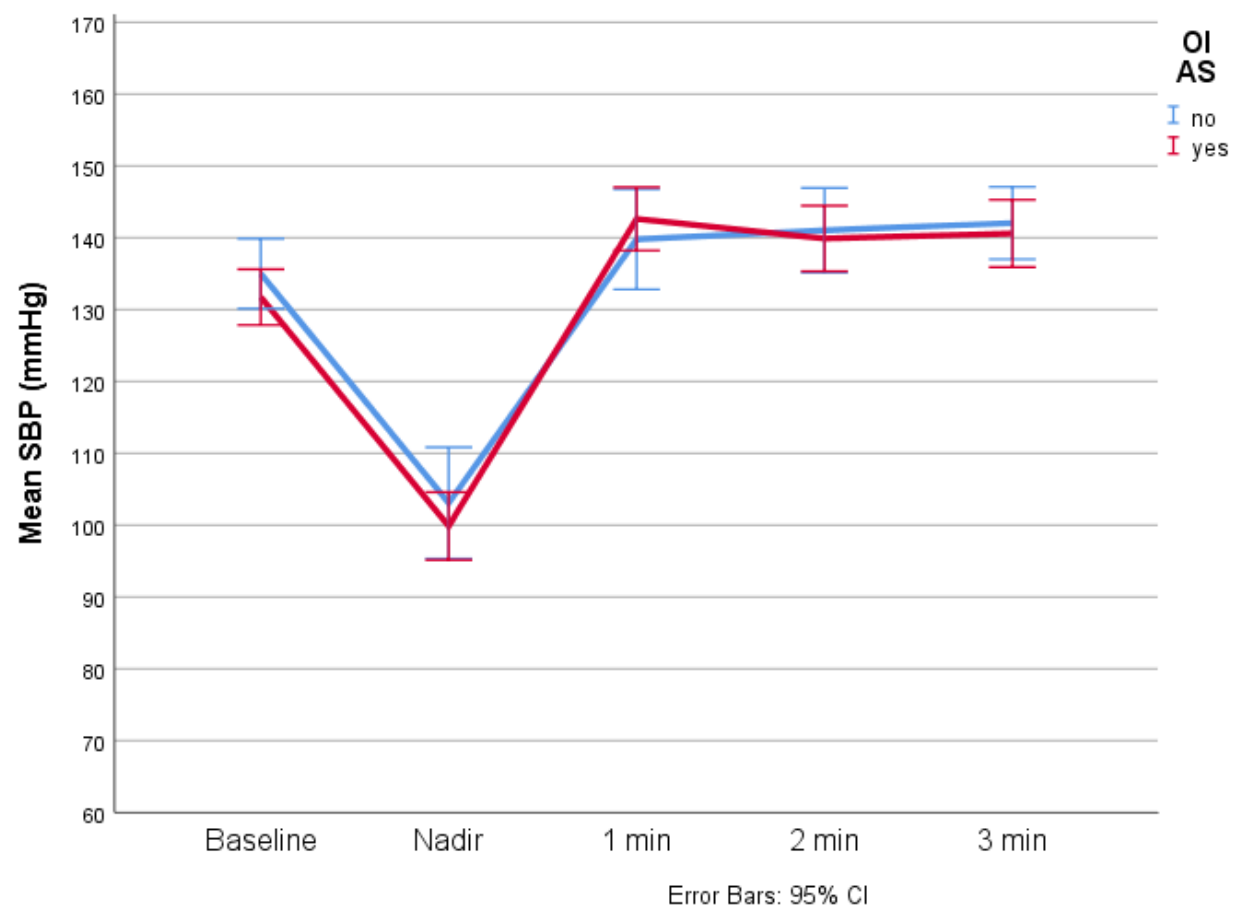

$\underline{\text { b: diastolic blood pressure (DBP) }}$

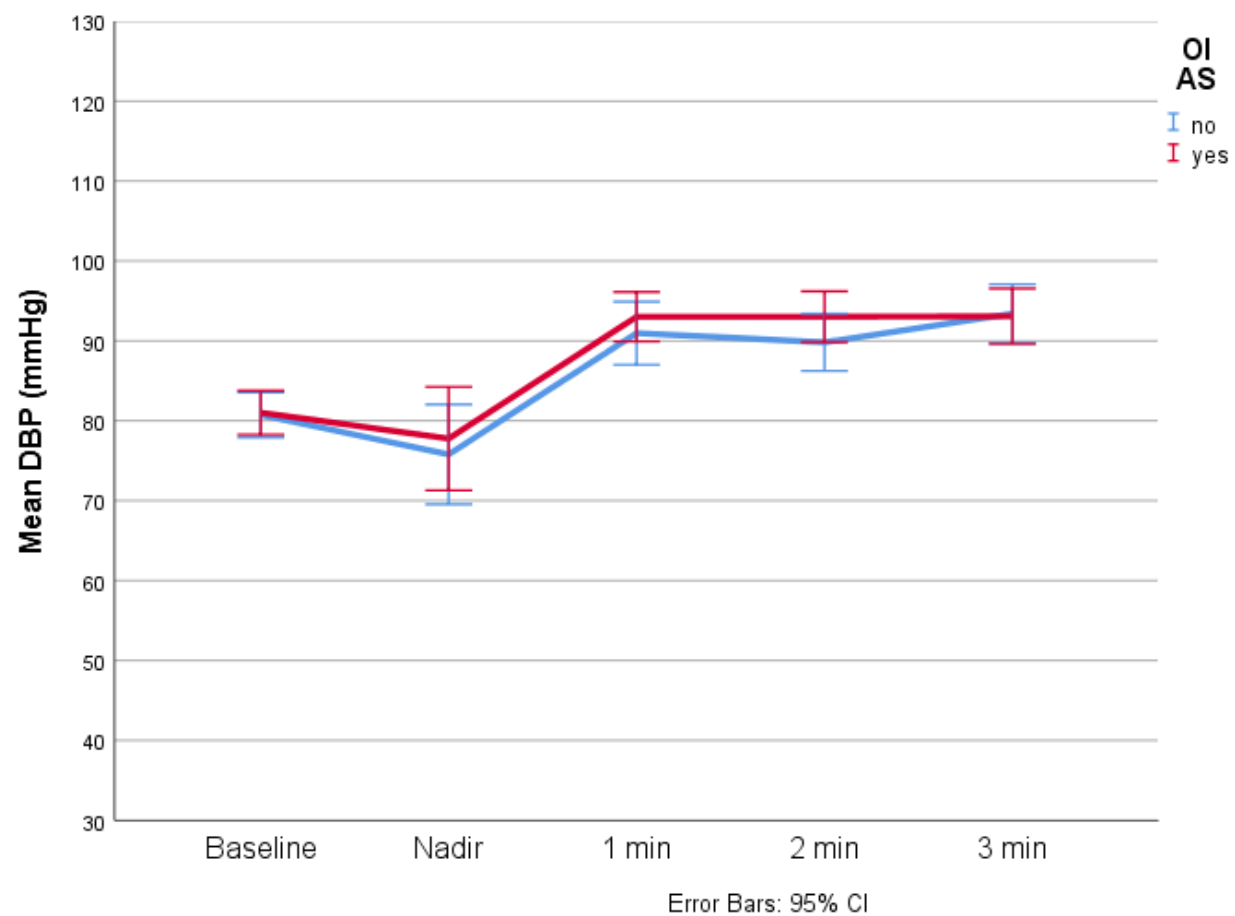

Error Bars: $95 \% \mathrm{Cl}$ 
medRxiv preprint doi: https://doi.org/10.1101/2021.12.19.21268060; this version posted December 21, 2021. The copyright holder for this preprint (which was not certified by peer review) is the author/funder, who has granted medRxiv a license to display the preprint in perpetuity.

$\underline{\mathrm{c}: \text { heart rate }(\mathrm{HR})}$

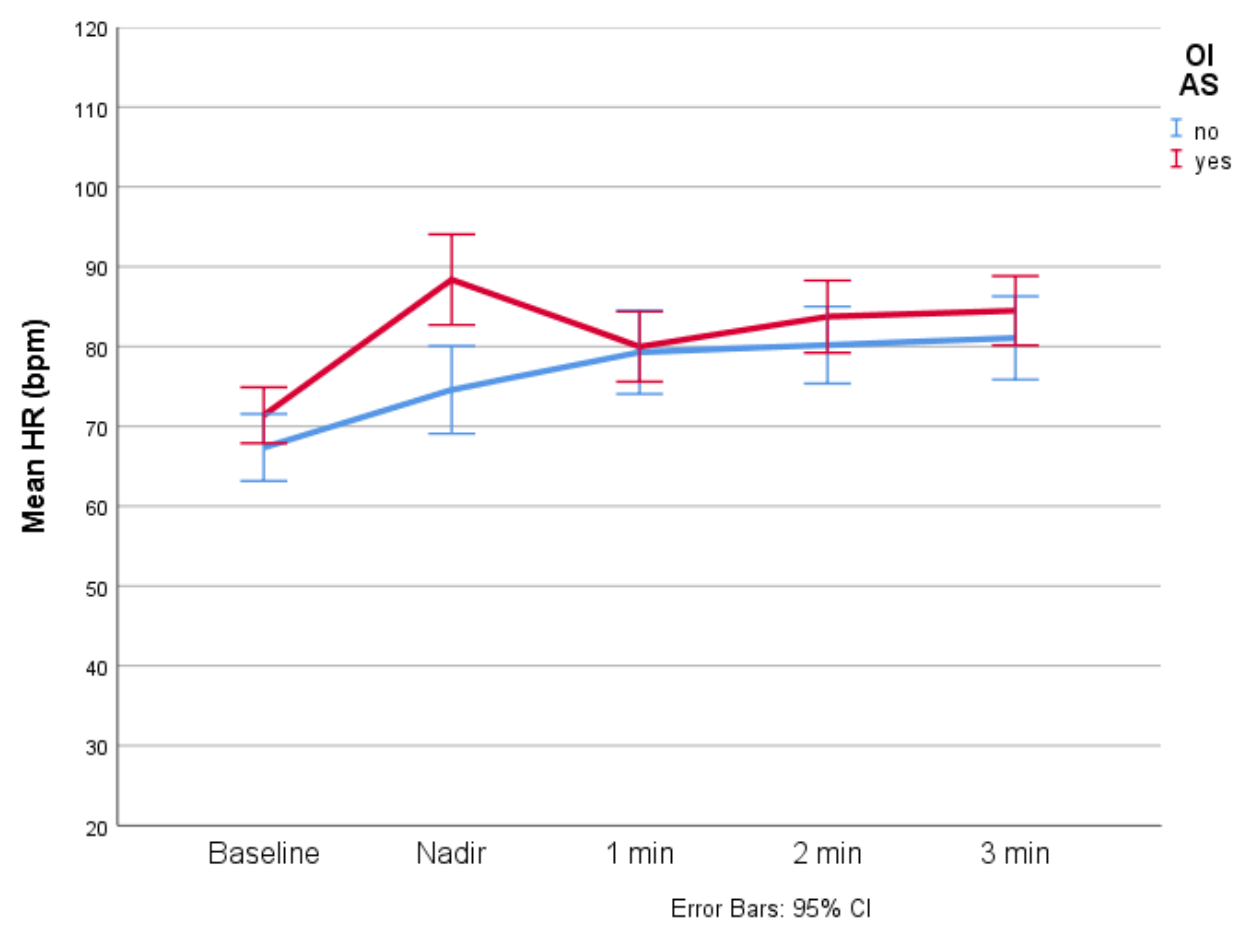

d: tissue saturation index (TSI)

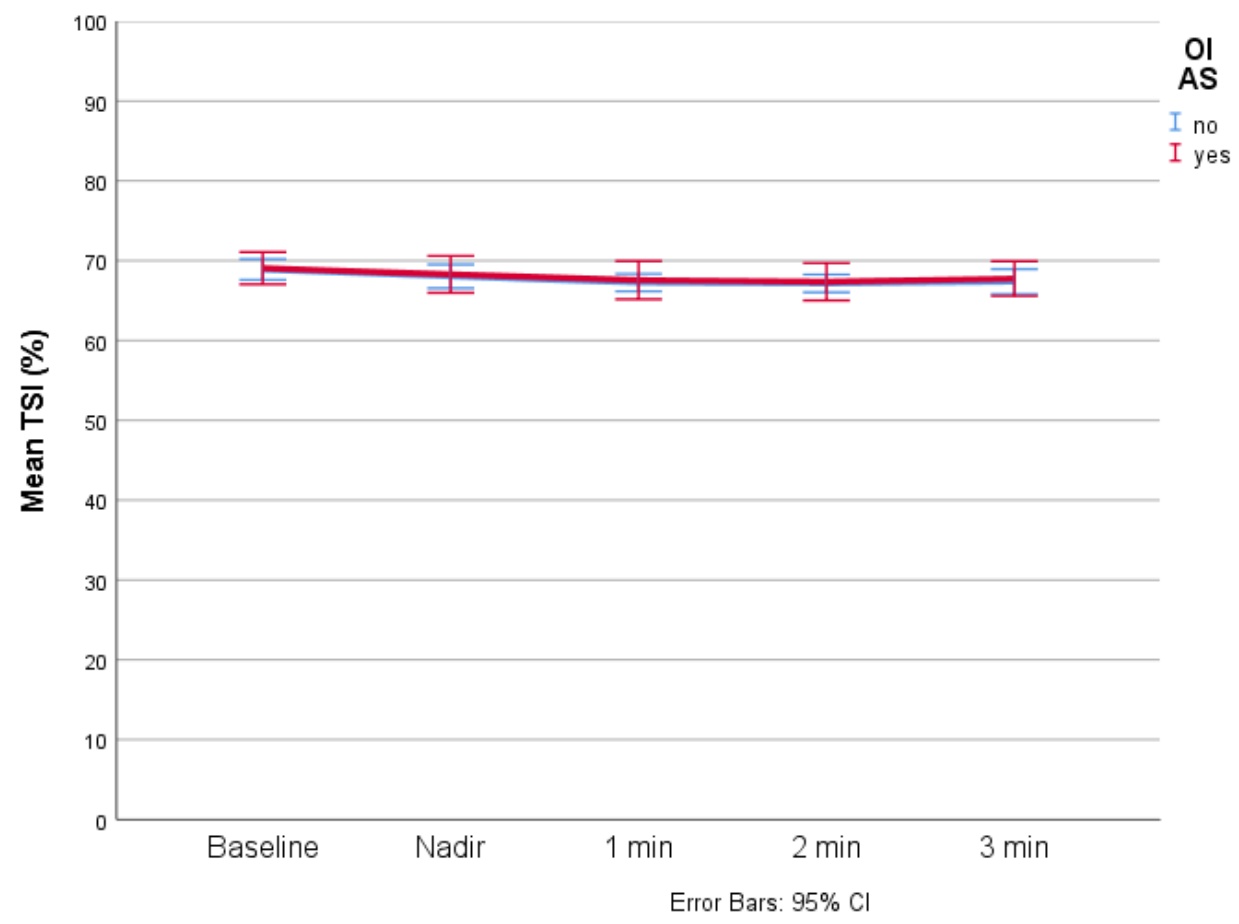

Error Bars: $95 \% \mathrm{Cl}$ 
331

332

333

334

335

336

337

338

339

340

341

342

343

344

345

346

347

348

349

350

351

352

353

354

355

356

357

358

359

360

361

362

363

364

365

366

367

368

In the logistic regression model to investigate predictors of $\mathrm{OI}_{\mathrm{AS}}$ (Table 3), the only significant predictor after controlling for age, sex, fatigue, depression, ADL inability, and peak HR after the nadir SBP, $\mathrm{HR}_{\text {nadir }}$ was the only $\mathrm{OI}_{\mathrm{AS}}$ predictor $(\mathrm{OR}=1.09,95 \% \mathrm{CI}: 1.01-1.18, \mathrm{P}=0.027)$.

Table 3. Logistic regression model with predictors of $\mathrm{OI}_{\mathrm{AS}}$. AS: active stand; CFQ: Chalder Fatigue Scale; CES-D: Center for Epidemiological Studies Depression scale; HR: heart rate; SBP: systolic blood pressure; OR: odds ratio; CI: confidence interval.

\begin{tabular}{|c|c|c|c|c|}
\hline & \multirow[t]{2}{*}{ OR } & \multicolumn{2}{|c|}{$95 \% \mathrm{CI}$ for OR } & \multirow[t]{2}{*}{$\mathrm{P}$} \\
\hline & & Lower & Upper & \\
\hline Age & 0.98 & 0.91 & 1.05 & 0.604 \\
\hline Female sex & 1.97 & 0.32 & 12.06 & 0.463 \\
\hline CFQ score & 0.96 & 0.80 & 1.16 & 0.666 \\
\hline CES-D score & 1.07 & 0.99 & 1.16 & 0.080 \\
\hline In the past month, I have had too little energy to do the things I wanted to do & 4.48 & 0.32 & 62.08 & 0.263 \\
\hline $\mathrm{HR}$ at nadir & 1.09 & 1.01 & 1.18 & 0.027 \\
\hline Peak HR after the nadir SBP & 0.97 & 0.89 & 1.06 & 0.495 \\
\hline
\end{tabular}

Of the 85 participants who had an AS, $71(83.5 \%)$ had a tilt table test. 14 participants did not have a tilt for reasons including history of recurrent vasovagal syncope (at least two lifetime episodes), a body weight $>120 \mathrm{Kg}$ (tilt table safety limit) or not consenting. All tilt participants had had an AS test. Of them, $28(39.4 \%)$ had OI during tilt $\left(\mathrm{OI}_{\text {tilt }}\right)$. The frequencies of $\mathrm{OI}_{\text {tilt }}$ symptoms were as follows: "slightly light-headed" (n=10,35.7\%), "light-headed" $(\mathrm{n}=8,28.6 \%)$, "slightly dizzy" $(\mathrm{n}=3$, $10.7 \%)$, “dizzy" (n=2, 7.1\%), "very light-headed" (n=1,3.6\%), "head spinning" ( $\mathrm{n}=1,3.6 \%)$, "drained" ( $\mathrm{n}=1,3.6 \%)$, "weak" $1(\mathrm{n}=1,3.6 \%)$, and "palpitations" $(\mathrm{n}=1,3.6 \%)$. No instances of arrhythmia or acute myocardial ischemia were detected in the continuous ECG trace. As regards OI agreement between AS and tilt, 78.6\% $(\mathrm{n}=22)$ of those who had $\mathrm{OI}_{\text {tilt }}$ had previously reported $\mathrm{OI}_{\mathrm{AS}}$ $(\mathrm{P}=0.020) .18$ of the 71 participants had an early tilt termination due to symptoms $\left(\mathrm{n}=2\right.$ before the $2^{\text {nd }}$ minute, $n=3$ before the $3^{\text {rd }}$ minute, $n=1$ before the $4^{\text {th }}$ minute, $n=2$ before the $5^{\text {th }}$ minute, $n=5$ before the $6^{\text {th }}$ minute, $n=2$ before the $8^{\text {th }}$ minute, and $n=3$ before the $10^{\text {th }}$ minute). Of all the early terminations, $13(72.2 \%)$ were terminated because of $\mathrm{OI}_{\text {tilt }}$ symptoms $(\mathrm{P}=0.001)$. The other 5 early tilt terminations were due to the development of "slight shortness of breath" $(n=1)$, "feet pain" $(n=1)$ and for reasons not related to development of symptoms $(n=3)$. No pre-syncope or syncope occurred in any of the participants. All $\mathrm{OI}_{\text {tilt }}$ symptoms were reported as transient.

Section 2 in the Supplementary Information shows the comparison between $\mathrm{OI}_{\text {tilt }}$ and non-OI $\mathrm{I}_{\text {tilt }}$ subgroups. 22 participants (33.3\% among the 66 with a tilt of at least 3 minutes) fulfilled criteria for $\mathrm{cOH}_{\text {tilt, }}$, and 7 (13.2\% among the 53 with a full 10-minute tilt) for POTS, and neither of the two $\left(\mathrm{P}=0.916\right.$ an $\mathrm{P}=0.233$, respectively) were significantly associated with $\mathrm{OI}_{\text {tilt. }}$. Among the $7 \mathrm{POTS}$ participants, 2 had a maximum head-up tilt $\mathrm{HR}$ of $\geq 120$ beats/minute, 6 had no $\mathrm{OI}_{\text {tilt }}$, 4 had reported $\mathrm{OI}_{\mathrm{AS}}, 2$ were on beta blockers, and 1 on antihypertensives. In the 18 participants whose tilt was terminated early, none of the available data fulfilled POTS criteria. As shown in the Supplementary Information, there were no statistically significant differences between $\mathrm{OI}_{\text {tilt }}$ subgroups across other clinical (section 2) or haemodynamic characteristics (sections 3 and 4), and no significant predictors of $\mathrm{OI}_{\text {tilt }}$ in the regression model (section 5). 


\section{Discussion}

370

371

372

373

374

375

376

377

378

379

380

In this study, we investigated predictors of orthostatic intolerance (OI) in adults with long COVID. OI during active stand $\left(\mathrm{OI}_{\mathrm{AS}}\right)$ was reported by $66 \%$ of our sample and seemed associated with female sex, more fatigue and depressive symptoms, and greater inability to perform activities of daily living, as well as a higher heart rate at the lowest systolic blood pressure point before the first minute poststand $\left(\mathrm{HR}_{\text {nadir }}\right)$. In a regression model also including age, sex, fatigue, depression, ADL inability, and peak HR after the nadir SBP, $\mathrm{HR}_{\text {nadir }}$ was the only $\mathrm{OI}_{\mathrm{AS}}$ predictor. $26 \%$ of participants had initial and $6 \%$ classical orthostatic hypotension, but neither correlated with $\mathrm{OI}_{\mathrm{AS}}$. Of the participants who had a tilt, 39\% had OI during tilt; and of the participants who completed a 10-minute tilt, $13 \%$ fulfilled hemodynamic POTS criteria, but most cases (6 out of 7) were asymptomatic.

The HR at the time of nadir SBP after stand seemed more important than the peak HR after the nadir $\mathrm{SBP}$ as a predictor of $\mathrm{OI}_{\mathrm{AS}}$. In this light, findings might reflect different baroreceptor-related HR responses in participants with $\mathrm{OI}_{\mathrm{AS}}$, possibly due to lower efferent vagus nerve activity, and/or higher sympathetic activation. In this regard, it has been described that with incomplete loss of baroreflex afferents, a mild syndrome of orthostatic tachycardia or orthostatic intolerance may appear; in some cases, it may primarily reflect interruption of efferent right vagus nerve activity, leading to a loss of parasympathetic input to the sinus node, with a consequent increase in heart rate; and in other cases, mild sympathetic activation may occur with stress and provoke tachycardia disproportionate to the increase in blood pressure (Ketch et al., 2002). Indeed, other authors have described the possibility of depressed vagal tone (Leitzke et al., 2020) with or without baroreceptor dysfunction that may lead to tachycardia and heightened cardiac contractility, vascular resistance and venous return (Becker, 2020).

While SARS $\square \operatorname{CoV} \square 2$ might be able to affect neurovascular integrity via direct cytotoxic or indirect pro-inflammatory mechanisms (Khosravani, 2021), our results are in the context of a high burden of psychological symptoms, which is in keeping with other reports (Bucciarelli et al., 2021;Qi et al., 2021). Given our recruitment focus, the proportion of fatigue in our cohort was higher than elsewhere (Akbarialiabad et al., 2021;Lopez-Leon et al., 2021;Sanchez-Ramirez et al., 2021;Sandler et al., 2021). For contextualization to our cohort, previous research showed that a CFQ score of 29 discriminated between chronic fatigue sufferers and controls in $96 \%$ of cases [36]; CES-D scores of 16 or greater can signal risk for clinical depression (Lewinsohn et al., 1997); and an IES-R score of 33 and above is suggestive of PTSD (Creamer et al., 2003). Even though in our regression model the $\mathrm{HR}_{\text {nadir }}$ finding seemed to eclipse previously significant univariate associations with depression and fatigue/ADL inability, adverse psychological states may influence the behaviour of the autonomic nervous system (Peckerman et al., 2003;De Vos et al., 2017); furthermore, in susceptible individuals, discrepancies between predicted and experienced interoceptive signals may engender anxiety during an acute physiological arousal (such as an active stand), which may manifest as transient tachycardia (Miglis and Muppidi, 2017; Owens et al., 2018).

In our cohort there seemed to be evidence of diastolic orthostatic hypertension, fulfilling on average the criterion of a rise in DBP $\geq 10 \mathrm{mmHg}$ within 3 minutes following AS (Jordan et al., 2020). The pathological significance of this finding is not clear and merits further investigation; indeed, orthostatic hypertension has been found in healthy subjects but also associated with higher (including hypertension) (Jordan et al., 2020) and lower (Wijkman et al., 2016) cardiovascular risks, with more research still needed to clarify its mechanisms and impacts (Jordan et al., 2020). Interestingly, even though orthostatic hypertension did not seem related to OI in our cohort, it has been described that some patients with chronic OI develop symptoms despite a hypertensive response to standing, 
417 suggesting that the symptoms of chronic OI may somehow be elicited by central responses to the

418 inappropriate tachycardia, even in the absence of any actual reduction in perfusion pressure

419

420 (Narkiewicz and Somers, 1998).

422

423

In a previous study where autonomic testing was conducted a median of 119 days following acute COVID-19 infection, 22\% of patients fulfilled the criteria for POTS (Shouman et al., 2021), in contrast with $13 \%$ in our sample with a median delay to testing of 302 days. As required for the POTS definition [39], 6 of our 7 hemodynamically identified POTS had chronic symptoms of OI lasting at least 6 months; however, in 6 out of 7 cases they did not have $\mathrm{OI}_{\text {tilt }}$ during testing, meaning good tolerability to the tilt challenge and potentially a better clinical prognosis. A previous case report showed no improvement in COVID-19-associated POTS symptoms approximately 5.5 months after symptom onset (Miglis et al., 2020); in a case series of 20 patients, it was reported that most (85\%) self-reported residual symptoms 6-8 months after COVID-19, although many felt that they had improved (Blitshteyn and Whitelaw, 2021). Three case reports have documented improvement in POTS after COVID-19 infection, with or without pharmacological support (Ishibashi et al., 2021; O'Sullivan et al., 2021;Ocher et al., 2021). To build on the anecdotal evidence, longitudinal studies are required to assess the evolution of post-COVID POTS in the same cohorts.

Our study has limitations. Firstly, from a study design perspective, generalisability of the findings cannot be assumed given the non-probabilistic recruitment. The evidence we presented is crosssectional and observational, hence causation cannot be inferred. In addition, we did not have a sample of controls, which can be beneficial in the study of long COVID (Amin-Chowdhury and Ladhani, 2021). Statistical underpower is likely, given the many instances where the statistic of choice for comparisons was the Fisher's exact test, and a small sample size that precluded inclusion of a greater number of predictors in the regression models.

Another limitation is that our testing protocol did not include other standardised autonomic tests such as heart rate variability with paced breathing or blood pressure response to Valsalva maneuver.

However, in the same clinical environment, Townsend et al. performed those tests on a different long COVID cohort and reported negative findings (Townsend et al., 2021). Our study did not have more detailed measures of baroreflex function, or any imaging or biomarker information (e.g., hematological, biochemical, immunological). For ethical approval reasons, in some cases our research tilts had to be stopped sooner (e.g., with only mild symptoms) than is often the case for tilts used in clinical practice to look for full symptom reproduction. From a haemodynamic data processing point of view, other studies have extracted the raw data from the Finapres® and performed signal averaging prior to analyses, for example in 5-second bins (van der Velde et al., 2007). While post-hoc signal averaging can theoretically reduce the risk of spurious observations due to signal artifacts (Finucane et al., 2019), in this study we followed the direct observation method that is routinely utilised in clinical practice for the contemporaneous clinical assessment of patients.

In conclusion, in our study $\mathrm{OI}_{\mathrm{AS}}$ was associated with a higher initial HR on AS, which after 1 minute equalized with the non-OI $\mathrm{AS}_{\mathrm{AS}}$ group, and POTS was infrequent and largely asymptomatic. The burden of psychological symptoms in this cohort was high and findings may be related to interoceptive mechanisms. However, more research is required to understand the mechanisms and long-term prognosis of autonomic function in long COVID, to better delineate therapies and estimate the need for services. 


\section{Conflict of Interest}

466

467

The authors declare that the research was conducted in the absence of any commercial or financial relationships that could be construed as a potential conflict of interest.

\section{Author Contributions}

Conceptualization: Roman Romero-Ortuno, Ann Monaghan; Methodology: Roman Romero-Ortuno, Ann Monaghan, Lisa Byrne; Clinical data collection: Ann Monaghan, Glenn Jennings, Feng Xue, Eoin Duggan, Roman Romero-Ortuno; Formal analysis and investigation: Roman Romero-Ortuno, Ann Monaghan, Glenn Jennings, Eoin Duggan; Writing - original draft preparation: Roman RomeroOrtuno; Writing - review and editing: Ann Monaghan, Glenn Jennings, Feng Xue, Eoin Duggan, Lisa Byrne; Funding acquisition: Roman Romero-Ortuno; Resources: Roman Romero-Ortuno, Lisa Byrne; Supervision: Eoin Duggan, Lisa Byrne, Roman Romero-Ortuno.

\section{$7 \quad$ Funding}

This study (Technology Assisted Solutions for the Recognition of Objective Physiological Indicators of Post-Coronavirus-19 Fatigue: TROPIC Study) was funded by a Grant from Science Foundation Ireland (SFI) under Grant number 20/COV/8493 and supported by SFI Grant number 18/FRL/6188. The funder had no role in the conduct of the research and/or preparation of the article; in study design; in the collection, analysis, and interpretation of data; in writing of the report; or in the decision to submit the paper for publication.

\section{Acknowledgments}

We are very grateful to our participants for their involvement in the study.

\section{$9 \quad$ References}

Akbarialiabad, H., Taghrir, M.H., Abdollahi, A., Ghahramani, N., Kumar, M., Paydar, S., Razani, B., Mwangi, J., Asadi-Pooya, A.A., Malekmakan, L., and Bastani, B. (2021). Long COVID, a comprehensive systematic scoping review. Infection.

Amin-Chowdhury, Z., and Ladhani, S.N. (2021). Causation or confounding: why controls are critical for characterizing long COVID. Nat Med 27, 1129-1130.

Barizien, N., Le Guen, M., Russel, S., Touche, P., Huang, F., and Vallee, A. (2021). Clinical characterization of dysautonomia in long COVID-19 patients. Sci Rep 11, 14042.

Becker, R.C. (2020). Anticipating the long-term cardiovascular effects of COVID-19. J Thromb Thrombolysis 50, 512-524.

Becker, R.C. (2021). Autonomic dysfunction in SARS-COV-2 infection acute and long-term implications COVID-19 editor's page series. J Thromb Thrombolysis.

Blitshteyn, S., and Whitelaw, S. (2021). Postural orthostatic tachycardia syndrome (POTS) and other autonomic disorders after COVID-19 infection: a case series of 20 patients. Immunol Res 69, 205-211.

Breeuwsma, A.C., Hartog, L.C., Kamper, A.M., Groenier, K.H., Bilo, H.J.G., Kleefstra, N., and Van Hateren, K.J.J. (2018). Diagnosing orthostatic hypotension with continuous and interval blood pressure measurement devices. J Hum Hypertens 32, 831-837.

Bucciarelli, V., Nasi, M., Bianco, F., Seferovic, J., Ivkovic, V., Gallina, S., and Mattioli, A.V. (2021). Depression pandemic and cardiovascular risk in the COVID-19 era and long COVID syndrome: gender makes a difference. Trends Cardiovasc Med. 
506

507

508

509

510

511

512

513

514

515

516

517

518

519

520

521

522

523

524

525

526

527

528

529

530

531

532

533

534

535

536

537

538

539

540

541

542

543

544

545

546

547

548

549

550

551

552

553

554

Cella, M., and Chalder, T. (2010). Measuring fatigue in clinical and community settings. $J$ Psychosom Res 69, 17-22.

Claffey, P., Perez-Denia, L., Rivasi, G., Finucane, C., and Kenny, R.A. (2020). Near-infrared spectroscopy in evaluating psychogenic pseudosyncope-a novel diagnostic approach. QJM 113, 239-244.

Creamer, M., Bell, R., and Failla, S. (2003). Psychometric properties of the Impact of Event Scale Revised. Behav Res Ther 41, 1489-1496.

Dani, M., Dirksen, A., Taraborrelli, P., Torocastro, M., Panagopoulos, D., Sutton, R., and Lim, P.B. (2021). Autonomic dysfunction in 'long COVID': rationale, physiology and management strategies. Clin Med (Lond) 21, e63-e67.

De Vos, A., De Keyser, J., and De Raedt, S. (2017). Role of infarct location and pre-existing depression on cardiac baroreceptor sensitivity in subacute ischemic stroke. Acta Neurol Belg 117, 655-659.

Del Rio, R., Marcus, N.J., and Inestrosa, N.C. (2020). Potential Role of Autonomic Dysfunction in Covid-19 Morbidity and Mortality. Front Physiol 11, 561749.

Figueroa, J.J., Cheshire, W.P., Claydon, V.E., Norcliffe-Kaufmann, L., Peltier, A., Singer, W., Snapper, H., Vernino, S., Raj, S.R., and American Autonomic, S. (2020). Autonomic function testing in the COVID-19 pandemic: an American Autonomic Society position statement. Clin Auton Res 30, 295-297.

Finucane, C., Van Wijnen, V.K., Fan, C.W., Soraghan, C., Byrne, L., Westerhof, B.E., Freeman, R., Fedorowski, A., Harms, M.P.M., Wieling, W., and Kenny, R. (2019). A practical guide to active stand testing and analysis using continuous beat-to-beat non-invasive blood pressure monitoring. Clin Auton Res 29, 427-441.

Freeman, R., Wieling, W., Axelrod, F.B., Benditt, D.G., Benarroch, E., Biaggioni, I., Cheshire, W.P., Chelimsky, T., Cortelli, P., Gibbons, C.H., Goldstein, D.S., Hainsworth, R., Hilz, M.J., Jacob, G., Kaufmann, H., Jordan, J., Lipsitz, L.A., Levine, B.D., Low, P.A., Mathias, C., Raj, S.R., Robertson, D., Sandroni, P., Schatz, I., Schondorff, R., Stewart, J.M., and Van Dijk, J.G. (2011). Consensus statement on the definition of orthostatic hypotension, neurally mediated syncope and the postural tachycardia syndrome. Clin Auton Res 21, 69-72.

Goldstein, D.S. (2020). The extended autonomic system, dyshomeostasis, and COVID-19. Clin Auton Res 30, 299-315.

Guaraldi, P., Barletta, G., Baschieri, F., Calandra-Buonaura, G., Provini, F., and Cortelli, P. (2020). Testing cardiovascular autonomic function in the COVID-19 era: lessons from Bologna's Autonomic Unit. Clin Auton Res 30, 325-330.

Ishibashi, Y., Yoneyama, K., Tsuchida, T., and Y, J.A. (2021). Post-COVID-19 Postural Orthostatic Tachycardia Syndrome. Intern Med 60, 2345.

Jennings, G., Monaghan, A., Xue, F., Mockler, D., and Romero-Ortuño, R. (2021). A systematic review of persistent symptoms and residual abnormal functioning following acute COVID19: Ongoing symptomatic phase vs. post-COVID-19 syndrome. medRxiv, 2021.2006.2025.21259372.

Johansson, M., Ståhlberg, M., Runold, M., Nygren-Bonnier, M., Nilsson, J., Olshansky, B., Bruchfeld, J., and Fedorowski, A. (2021). Long-Haul Post-COVID-19 Symptoms Presenting as a Variant of Postural Orthostatic Tachycardia Syndrome: The Swedish Experience. JACC: Case Reports 3, 573-580.

Jordan, J., Ricci, F., Hoffmann, F., Hamrefors, V., and Fedorowski, A. (2020). Orthostatic Hypertension: Critical Appraisal of an Overlooked Condition. Hypertension 75, 1151-1158.

Ketch, T., Biaggioni, I., Robertson, R., and Robertson, D. (2002). Four faces of baroreflex failure: hypertensive crisis, volatile hypertension, orthostatic tachycardia, and malignant vagotonia. Circulation 105, 2518-2523. 
Keyhanian, K., Umeton, R.P., Mohit, B., Davoudi, V., Hajighasemi, F., and Ghasemi, M. (2020). SARS-CoV-2 and nervous system: From pathogenesis to clinical manifestation. $J$ Neuroimmunol 350, 577436.

Khosravani, H. (2021). The Dysfunction is in the Details: Neurovascular Changes in COVID-19. Can J Neurol Sci 48, 1-2.

Larsen, N.W., Stiles, L.E., and Miglis, M.G. (2021). Preparing for the long-haul: Autonomic complications of COVID-19. Auton Neurosci 235, 102841.

Leitzke, M., Stefanovic, D., Meyer, J.J., Schimpf, S., and Schonknecht, P. (2020). Autonomic balance determines the severity of COVID-19 courses. Bioelectron Med 6, 22.

Lewinsohn, P.M., Seeley, J.R., Roberts, R.E., and Allen, N.B. (1997). Center for Epidemiologic Studies Depression Scale (CES-D) as a screening instrument for depression among community-residing older adults. Psychology and Aging 12, 277-287.

Lopez-Leon, S., Wegman-Ostrosky, T., Perelman, C., Sepulveda, R., Rebolledo, P.A., Cuapio, A., and Villapol, S. (2021). More than 50 long-term effects of COVID-19: a systematic review and meta-analysis. Scientific reports 11, 16144-16144.

Michelen, M., Manoharan, L., Elkheir, N., Cheng, V., Dagens, A., Hastie, C., O'hara, M., Suett, J., Dahmash, D., Bugaeva, P., Rigby, I., Munblit, D., Harriss, E., Burls, A., Foote, C., Scott, J., Carson, G., Olliaro, P., Sigfrid, L., and Stavropoulou, C. (2021). Characterising long COVID: a living systematic review. BMJ Glob Health 6.

Miglis, M.G., and Muppidi, S. (2017). Is postural tachycardia syndrome in the head or in the heart? And other updates on recent autonomic research. Clin Auton Res 27, 145-147.

Miglis, M.G., Prieto, T., Shaik, R., Muppidi, S., Sinn, D.I., and Jaradeh, S. (2020). A case report of postural tachycardia syndrome after COVID-19. Clin Auton Res 30, 449-451.

Munoz-Bermejo, L., Adsuar, J.C., Mendoza-Munoz, M., Barrios-Fernandez, S., Garcia-Gordillo, M.A., Perez-Gomez, J., and Carlos-Vivas, J. (2021). Test-Retest Reliability of Five Times Sit to Stand Test (FTSST) in Adults: A Systematic Review and Meta-Analysis. Biology (Basel) 10.

Narkiewicz, K., and Somers, V.K. (1998). Chronic orthostatic intolerance: part of a spectrum of dysfunction in orthostatic cardiovascular homeostasis? Circulation 98, 2105-2107.

O'sullivan, J.S., Lyne, A., and Vaughan, C.J. (2021). COVID-19-induced postural orthostatic tachycardia syndrome treated with ivabradine. BMJ Case Rep 14.

Ocher, R.A., Padilla, E., Hsu, J.C., and Taub, P.R. (2021). Clinical and Laboratory Improvement in Hyperadrenergic Postural Orthostatic Tachycardia Syndrome (POTS) after COVID-19 Infection. Case Rep Cardiol 2021, 7809231.

Owens, A.P., Low, D.A., Critchley, H.D., and Mathias, C.J. (2018). Emotional orienting during interoceptive threat in orthostatic intolerance: Dysautonomic contributions to psychological symptomatology in the postural tachycardia syndrome and vasovagal syncope. Auton Neurosci 212, 42-47.

Paterson, I., Ramanathan, K., Aurora, R., Bewick, D., Chow, C.M., Clarke, B., Cowan, S., Ducharme, A., Gin, K., Graham, M., Gupta, A., Jassal, D.S., Kazmi, M., Krahn, A., Lamarche, Y., Marelli, A., Roifman, I., Ruel, M., Singh, G., Sterns, L., Turgeon, R., Virani, S., Wong, K.K., and Zieroth, S. (2021). Long COVID-19: A Primer for Cardiovascular Health Professionals, on Behalf of the CCS Rapid Response Team. Can J Cardiol 37, 12601262.

Peckerman, A., Lamanca, J.J., Qureishi, B., Dahl, K.A., Golfetti, R., Yamamoto, Y., and Natelson, B.H. (2003). Baroreceptor reflex and integrative stress responses in chronic fatigue syndrome. Psychosom Med 65, 889-895. 
medRxiv preprint doi: https://doi.org/10.1101/2021.12.19.21268060; this version posted December 21, 2021. The copyright holder for this preprint (which was not certified by peer review) is the author/funder, who has granted medRxiv a license to display the preprint in perpetuity.

It is made available under a CC-BY-NC-ND 4.0 International license .

Running Title

602

603

604

605

606

607

608

609

610

611

612

613

614

615

616

617

618

619

620

621

622

623

624

625

626

627

628

629

630

631

632

633

634

635

636

637

638

639

640

641

642

643

644

645

646

647

648

649

650

Qi, T., Hu, T., Ge, Q.Q., Zhou, X.N., Li, J.M., Jiang, C.L., and Wang, W. (2021). COVID-19 pandemic related long-term chronic stress on the prevalence of depression and anxiety in the general population. BMC Psychiatry 21, 380.

Radloff, L.S. (1977). The CES-D scale: A self report depression scale for research in the general population. Applied Psychological Measurements 1, 385-401.

Raj, S.R., Arnold, A.C., Barboi, A., Claydon, V.E., Limberg, J.K., Lucci, V.M., Numan, M., Peltier, A., Snapper, H., Vernino, S., and American Autonomic, S. (2021). Long-COVID postural tachycardia syndrome: an American Autonomic Society statement. Clin Auton Res 31, 365368.

Rank, A., Tzortzini, A., Kling, E., Schmid, C., Claus, R., Loll, E., Burger, R., Rommele, C., Dhillon, C., Muller, K., Girl, P., Hoffmann, R., Grutzner, S., and Dennehy, K.M. (2021). One Year after Mild COVID-19: The Majority of Patients Maintain Specific Immunity, But One in Four Still Suffer from Long-Term Symptoms. J Clin Med 10.

Rogers, J.P., Watson, C.J., Badenoch, J., Cross, B., Butler, M., Song, J., Hafeez, D., Morrin, H., Rengasamy, E.R., Thomas, L., Ralovska, S., Smakowski, A., Sundaram, R.D., Hunt, C.K., Lim, M.F., Aniwattanapong, D., Singh, V., Hussain, Z., Chakraborty, S., Burchill, E., Jansen, K., Holling, H., Walton, D., Pollak, T.A., Ellul, M., Koychev, I., Solomon, T., Michael, B.D., Nicholson, T.R., and Rooney, A.G. (2021). Neurology and neuropsychiatry of COVID-19: a systematic review and meta-analysis of the early literature reveals frequent CNS manifestations and key emerging narratives. J Neurol Neurosurg Psychiatry 92, 932-941.

Sanchez-Ramirez, D.C., Normand, K., Zhaoyun, Y., and Torres-Castro, R. (2021). Long-Term Impact of COVID-19: A Systematic Review of the Literature and Meta-Analysis.

Biomedicines 9.

Sandler, C.X., Wyller, V.B.B., Moss-Morris, R., Buchwald, D., Crawley, E., Hautvast, J., Katz, B.Z., Knoop, H., Little, P., Taylor, R., Wensaas, K.A., and Lloyd, A.R. (2021). Long COVID and Post-infective Fatigue Syndrome: A Review. Open Forum Infect Dis 8, ofab440.

Shah, W., Hillman, T., Playford, E.D., and Hishmeh, L. (2021). Managing the long term effects of covid-19: summary of NICE, SIGN, and RCGP rapid guideline. BMJ 372, n136.

Shouman, K., Vanichkachorn, G., Cheshire, W.P., Suarez, M.D., Shelly, S., Lamotte, G.J., Sandroni, P., Benarroch, E.E., Berini, S.E., Cutsforth-Gregory, J.K., Coon, E.A., Mauermann, M.L., Low, P.A., and Singer, W. (2021). Autonomic dysfunction following COVID-19 infection: an early experience. Clin Auton Res 31, 385-394.

Sinn, D.I., Muppidi, S., Miglis, M.G., and Jaradeh, S. (2021). Autonomic function test during the COVID-19 pandemic: the Stanford experience. Clin Auton Res 31, 127-129.

Townsend, L., Moloney, D., Finucane, C., Mccarthy, K., Bergin, C., Bannan, C., and Kenny, R.A. (2021). Fatigue following COVID-19 infection is not associated with autonomic dysfunction. PLoS One 16, e0247280.

Van Der Velde, N., Van Den Meiracker, A.H., Stricker, B.H., and Van Der Cammen, T.J. (2007). Measuring orthostatic hypotension with the Finometer device: is a blood pressure drop of one heartbeat clinically relevant? Blood Press Monit 12, 167-171.

Van Kessel, S.a.M., Olde Hartman, T.C., Lucassen, P., and Van Jaarsveld, C.H.M. (2021). Post-acute and long-COVID-19 symptoms in patients with mild diseases: a systematic review. Fam Pract.

Vanichkachorn, G., Newcomb, R., Cowl, C.T., Murad, M.H., Breeher, L., Miller, S., Trenary, M., Neveau, D., and Higgins, S. (2021). Post-COVID-19 Syndrome (Long Haul Syndrome): Description of a Multidisciplinary Clinic at Mayo Clinic and Characteristics of the Initial Patient Cohort. Mayo Clin Proc 96, 1782-1791.

Von Elm, E., Altman, D.G., Egger, M., Pocock, S.J., Gotzsche, P.C., Vandenbroucke, J.P., and Initiative, S. (2007). The Strengthening the Reporting of Observational Studies in 
medRxiv preprint doi: https://doi.org/10.1101/2021.12.19.21268060; this version posted December 21, 2021. The copyright holder for this preprint (which was not certified by peer review) is the author/funder, who has granted medRxiv a license to display the preprint in perpetuity.

651

652

653

654

655

656

657

658

659

660

661

662

663

664

665

666

667

668

669

670

671

672

673

674
Epidemiology (STROBE) statement: guidelines for reporting observational studies. Lancet 370, 1453-1457.

Wesseling, K.H. (1996). Finger arterial pressure measurement with Finapres. Z Kardiol 85 Suppl 3, 38-44.

Who (2021). A clinical case definition of post COVID-19 condition by a Delphi consensus: 6 October 2021. Available online: https://www. who.int/publications/i/item/WHO-2019-nCoVPost_COVID-19_condition-Clinical_case_definition-2021.1 (accessed 26 October 2021).

Wieling, W., Krediet, C.T., Van Dijk, N., Linzer, M., and Tschakovsky, M.E. (2007). Initial orthostatic hypotension: review of a forgotten condition. Clin Sci (Lond) 112, 157-165.

Wijkman, M., Lanne, T., Ostgren, C.J., and Nystrom, F.H. (2016). Diastolic orthostatic hypertension and cardiovascular prognosis in type 2 diabetes: a prospective cohort study. Cardiovasc Diabetol 15, 83.

Yan, Z., Yang, M., and Lai, C.L. (2021). Long COVID-19 Syndrome: A Comprehensive Review of Its Effect on Various Organ Systems and Recommendation on Rehabilitation Plans. Biomedicines 9.

Yong, S.J. (2021). Long COVID or post-COVID-19 syndrome: putative pathophysiology, risk factors, and treatments. Infect Dis (Lond) 53, 737-754.

Zarei, M., Bose, D., Nouri-Vaskeh, M., Tajiknia, V., Zand, R., and Ghasemi, M. (2021). Long-term side effects and lingering symptoms post COVID-19 recovery. Rev Med Virol, e2289.

\section{Supplementary Material}

Please see the Supplementary Material section for further information.

\section{Data Availability Statement}

The datasets generated and analyzed for this study are not publicly available due to ethical approval reasons. 